\title{
The Primary Structures of Growth Hormones of Three Cyprinid Species: Bighead Carp, Silver Carp, and Grass Carp
}

\author{
Y. S. Chang, ${ }^{*} \dagger$ C. S. LiU, ${ }^{*}+$ F. L. Huang, ${ }^{*} \dagger$ AND T. B. Lo ${ }^{*} \dagger$ \\ *Institute of Biological Chemistry, Academia Sinica, †Graduate Institute of Biochemical Sciences, and \\ Department of Zoology, National Taiwan University, P.O. Box 23-106, Taipei, Taiwan
}

\author{
Accepted February 1, 1992
}

\begin{abstract}
The primary structures of growth hormone $(\mathrm{GH})$ of three cyprinid species, bighead carp, silver carp, and grass carp, were determined by a chemical method and/or by molecular cloning. The bighead carp GH was extracted from pituitary tissue by use of an alkaline medium, then successively purified by gel filtration, hydrophobic interaction column chromatography, and reverse-phase high-pressure liquid chromatography. The primary structure of bighead carp GH determined chemically is identical to that deduced from the cDNA nucleotide sequence. By molecular cloning, the primary structures of silver carp and grass carp GHs were also determined. The GHs of these three cyprinid species all contain 188 amino acid residues and their sequences are identical. When four of the five cysteines of cyprinid GHs were arranged to match the same positions of cysteines of other vertebrate GHs, a maximally matched alignment was achieved. Among fishes, GHs are relatively conserved within the same order ( 82 to $100 \%$ identity) but they are more diversified between orders (49 to $68 \%$ identity). In further comparison, fish GHs are even more different from tetrapod GHs (37 to 58\% identity). Although the primary structures of vertebrate GHs are relatively variable, four homologous sequences, notably one located at the $\mathrm{C}$-terminal, are found. @ 1992 Academic Press, Inc.
\end{abstract}

Growth hormone (GH), a polypeptide hormone secreted from pituitary gland, is required for normal growth and development. GH, together with prolactin and chorionic somatomammotropin, form a family of peptide hormones of similar structure and function. It has been suggested that they have evolved from a common ancestral gene by duplication (Nicoll et al., 1986). The primary structures of GH from several species of vertebrates have been determined, including mammals (Graf and Li, 1974; Martial et al., 1979; Barta et al., 1981; Yamano et al., 1988), birds (Souza et al., 1984; Chen et al., 1988), reptiles (Yasuda et al., 1989), amphibians (Pan and Chang, 1988), and fish (Agellon and Chen, 1986; Nicoll et al., 1987; Yamaguchi et al., 1987, 1989; Noso et al., 1988; Sato et al., 1988; Watahiki et al., 1988; Ho et al., 1989; Koren et al., 1989; Rentier-Delrue et al.,
1989; Liu et al., 1991). The available information indicates that fish GHs are very diversified.

In order to obtain more information about the molecular evolution of GH, we have determined the primary structures of GHs of three species of Cyprinidae, bighead carp (Hypophthalmichthys nobilis), silver carp (H. molitrix), and grass carp (Ctenopharyngodon idellus) by a chemical method and/or by cDNA cloning technique. Their nucleotide sequences and amino acid sequences are reported here and their amino acid sequences are compared to the GHs of other species of fish and tetrapods.

\section{MATERIALS AND METHODS}

Materials. The enzymes and high-pressure liquid chromatography (HPLC) products were purchased from the following sources: lysyl endopeptidase from 
Wako Pure Chemical Industry Ltd., Osaka, Japan: sequencing-grade trypsin from Boehringer, Mannheim, Germany; TSK-ODS-12OT column $(4.6 \times 250 \mathrm{~mm})$ and TSK Phenyl 5PW column $(7.5 \times 100 \mathrm{~mm})$ from Toyo Soda Mfg. Ltd., Tokyo, Japan; Nucleosil $\mathrm{C}_{18}$ $(4.6 \times 250 \mathrm{~mm})$ and Synchropak $\mathrm{C}_{4}$ column $(4.6 \times 250$ $\mathrm{mm})$ were self-packed. All other reagents and solvents were of the highest grade available commercially.

Isolation and purification of growth hormone. Bighead carp pituitary glands were collected in ice-water, ruptured by brief sonication, freeze-dried, and stored at $-20^{\circ}$ until use. To isolate $\mathrm{GH}$, pituitary powder $(0.25 \mathrm{~g})$ was suspended in $10 \mathrm{ml}$ of $0.02 \mathrm{M}$ Tris- $\mathrm{HCl}$ buffer ( $\mathrm{pH} 9.0$ ) containing $1 \mathrm{mM}$ phenylmethylsulfonyl fluoride, $10 \mu \mathrm{g} / \mathrm{ml}$ leupeptin, $1 \mathrm{~m} M$ ethylenediamine tetraacetic acid, and $5 \mathrm{~m} M$ sodium iodoacetate. After gentle stirring at $4^{\circ}$ for $3 \mathrm{hr}$, supernatant was obtained by centrifugation $\left(18,000 \mathrm{~g}, 30 \mathrm{~min}\right.$ at $\left.4^{\circ}\right)$. This is the crude extract of $\mathrm{GH}$.

To purify GII, the crude extract was applied to a column of superfine Sephadex G-75 $(1.5 \times 110 \mathrm{~cm})$ equilibrated with $0.05 M$ ammonium bicarbonate, $\mathrm{pH}$ 9.0 , and eluted with the same solution containing the above-mentioned protease inhibitors at a flow rate of $6.0 \mathrm{ml} / \mathrm{hr}$ at room temperature. The $\mathrm{GH}$-containing fraction was freeze-dried, dissolved in buffer A (10 $\mathrm{m} M$ sodium phosphate buffer, $\mathrm{pH} 7.0$, containing $1 M$ ammonium sulfate), and then subjected to hydrophobic interaction column chromatography in tandem columns of TSK phenyl 5 PW equilibrated with buffer A. The column was first eluted at a flow rate of $1 \mathrm{ml} / \mathrm{min}$ with buffer A for $15 \mathrm{~min}$, then eluted with a linear gradient of buffer A to buffer B ( $10 \mathrm{~m} M$ sodium phosphate buffer, $\mathrm{pH} 7.0$ ) for $60 \mathrm{~min}$, and finally eluted with buffer $B$ for $15 \mathrm{~min}$. The $\mathrm{GH}$-containing peak was collected and purified by reverse-phase (rp) HPLC, first using the Synchropak $\mathrm{C}_{4}$ column and then the TSK ODS $120 \mathrm{~T}$ column. The Synchropak $\mathrm{C}_{4}$ column was equilibrated with a mixture of $80 \%$ solvent $A$ (0.07\% trifluoroacetic acid, TFA) and $20 \%$ solvent B (0.07\% TFA in acetonitrile) and the sample was eluted with a linear gradient of solvent $B$ which reached from 20 to $70 \%$ within $60 \mathrm{~min}$ at a flow rate of $1 \mathrm{ml} / \mathrm{min}$. For operation of the TSK ODS $120 \mathrm{~T}$ column, it was equilibrated with a mixture of $65 \%$ solvent $\mathrm{A}$ and $35 \%$ solvent $B$ and the sample was eluted with a linear gradient of solvent $B$ which reached from 35 to $65 \%$ within 45 min at a flow rate of $1 \mathrm{ml} / \mathrm{min}$. Sodium dodecyl sulfatepolyacrylamide gel electrophoresis (SDS-PAGE) was used to monitor $\mathrm{GH}$ which appears as a band with molecular weight (MW) of 20,000.

Sequence determination. Reduction and alkylation of $\mathrm{GH}$ and desalting of reduced carboxymethylated (RCM)-GH by HPLC were performed as described previously (Liu et al., 1989). Cleavage of RCM-GH by lysyl endopeptidase was carried out in $50 \mathrm{mM}$ Tris$\mathrm{HCl}$ buffer ( $\mathrm{pH} \mathrm{9.0)}$ in $4 \mathrm{M}$ guanidine $\mathrm{HCl}$ at $37^{\circ}$ for 5 hr. A part of lysyl endopeptidase digest was dissolved in $0.3 \mathrm{ml}$ of $50 \mathrm{mM}$ Tris- $\mathrm{HCl}$ buffer ( $\mathrm{pH} 8.0$ ) and further treated with trypsin at $37^{\circ}$ for $18 \mathrm{hr}$. The resulting peptides were separated on a Nucleosil $C_{18}$ column. For operation, the column was equilibrated with a mixture of $90 \%$ solvent $A$ and $10 \%$ solvent $B$ and the sample was eluted with a linear gradient of solvent B which reached from 10 to $60 \%$ within 90 min at a flow rate of $1 \mathrm{ml} / \mathrm{min}$. Microscale amino acid analysis was achieved by a method described previously (Chang and Liu, 1988). Amino acid sequence was determined by means of a pulsed-liquid-type Model 477A sequenator (Applied Biosystems, Forster City, CA) in combination with an on-line phenylthiohydantoin amino acid analyzer.

Construction of cDNA library, screening, and sequencing of $G H$ CDNA. The methods used to construct pituitary cDNA libraries of bighead carp, silver carp, and grass carp were essentially the same as previously described (Chang et al., 1990). Briefly, the pituitary polyadenylated mRNAs were prepared by the guanidinium/ $\mathrm{CsCl}$ method followed by oligo(dT) cellulose column chromatography. Double-stranded cDNA was synthesized, ligated with EcoRI linker, and then cloned into pUC 19. Carp GH (cGH) cDNA was used as probe to screen the clones containing the cDNA encoding $\mathrm{GH}$ of bighead carp (bcGH), silver carp (scGH), and grass carp (gcGH).

The cDNAs encoding bcGH, scGH, and gcGH were cleaved with HincII for subcloning. The nucleotide sequences were determined by the dideoxynucleotide chain termination method (Sanger et al., 1977).

\section{RESULTS}

\section{Purification of Bighead Carp GH}

By Sephadex G-75 gel filtration, $43 \mathrm{mg}$ of $\mathrm{GH}$ containing fraction was obtained from $250 \mathrm{mg}$ of pituitary powder (data not shown). The GH fraction from gel filtration was further fractionated by hydrophobic interaction column chromatography. The GH-corresponding peak accounted for $33 \%$ of the applied sample (data not shown). Final purification was accomplished by two rpHPLC (Fig. 1). At this stage, GH became more or less insoluble so that the final yield could not be assessed. The purity of $\mathrm{GH}$ was ascertained by SDS-PAGE which reveals one major band of MW 20,000 and one minor band of MW 40,000 (Fig. 2). 

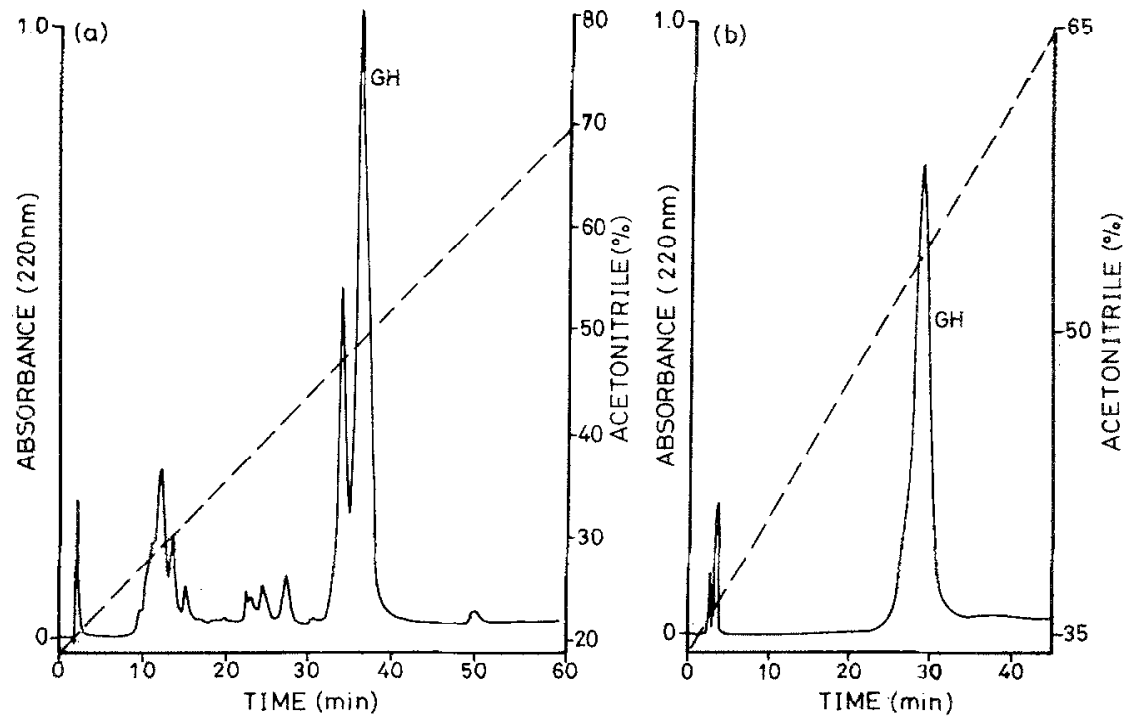

FIG. 1. Separation of bighead carp GH by HPLC. (a) About 1.5-mg sample from hydrophobic interaction column chromatography was injected onto a Synchropak $\mathrm{C}_{4}$ column. (b) Chromatography of GH fraction from (a) on a TSK ODS $120 \mathrm{~T}$ column.

\section{Sequencing of Peptide Fragments}

The peptide map of lysyl endopeptide digestion is presented in Fig. 3. Fourteen prominent peaks were separated. Among them, peaks LE-1, LE-7, LE-9, and LE-13 produced unique sequence while peaks LE-4 and LE-8 gave two different sequences. For LE-4, the 2 residues from each sequencing step had a peak area ratio of 11:1. Therefore, such difference was used to distinguish the sequences of LE-4-1 and LE-4-2 which began from positions 166 (LE-4-1) and 169 (LE-4-2), respectively. However, LE-8 gave two sequences in about the same intensity. One of the 2 residues of each sequencing step was identical to the residue determined from the $\mathrm{N}$-terminus of intact $\mathrm{GH}$. The peptide with the same sequence of the first $23 \mathrm{~N}$-terminal residues was denoted as LE-8-1. The sequence of other peptide, LE-8-2, was then determined by subtracting the residues of LE-8-1 from LE-8. Other missing sequences were complemented by peptides resulting from double digestion of lysyl en-

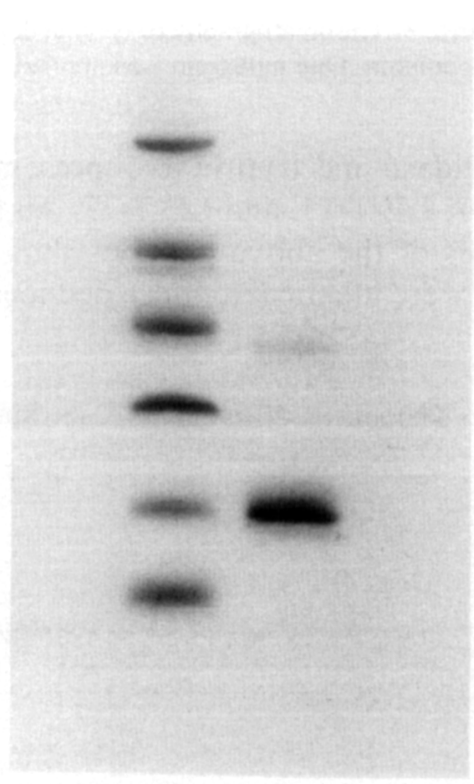

FIG. 2. Sodium dodecyl sulfate-polyacrylamide gel electrophoresis (SDS-PAGE) of bighead carp GH. The sample was dissolved in Tris- $\mathrm{HCl}$ buffer, $\mathrm{pH} 6.8$, containing $1.6 \%$ SDS and $0.1 \% 2$-mercaptoethanol and heated at $100^{\circ}$ for $10 \mathrm{~min}$, then loaded to $10 \%$ gel. Left lane, protein markers (from top to bottom) with molecular weights $94,000,67,000,43,00030,000,20,100$, and 14,400; right lane, bighead carp GH. 


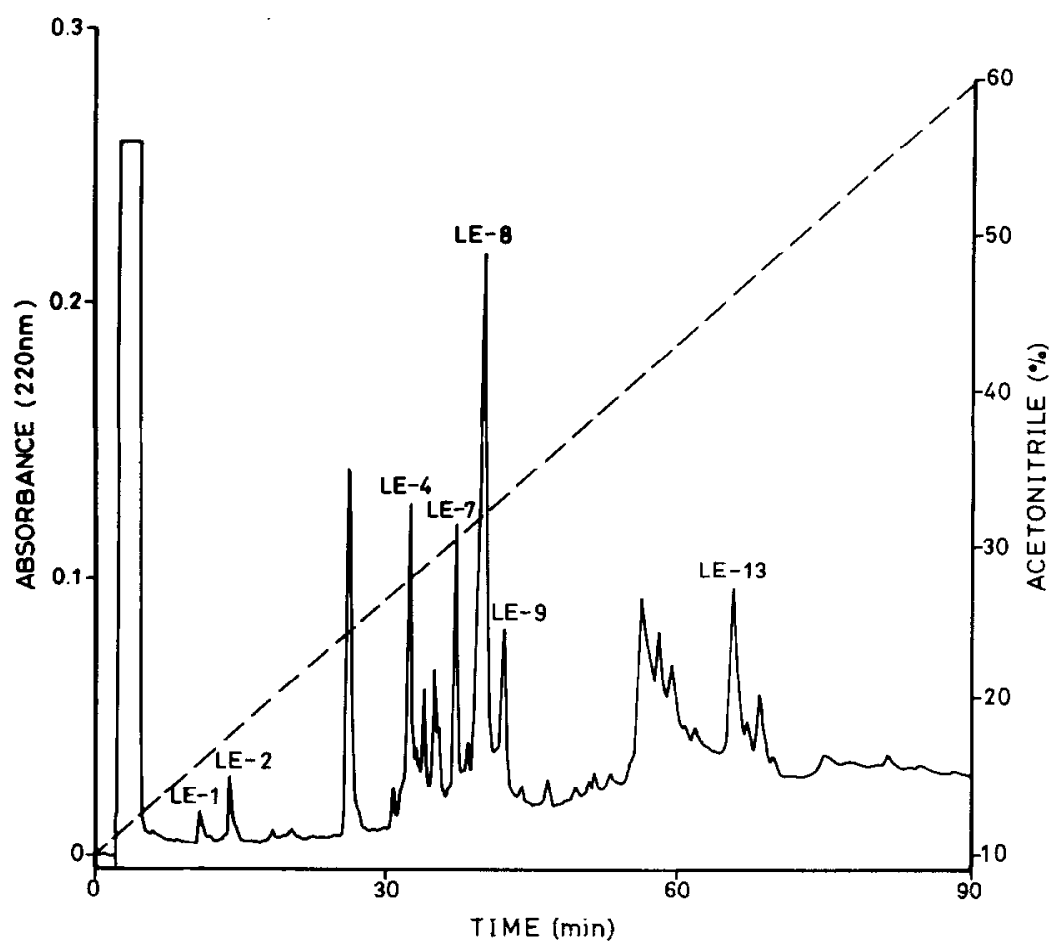

FIG. 3. Chromatography of lysyl endopeptidase (LE) digestion of bighead carp GH on an Nucleosil $\mathrm{C}_{18}$ column. One milligram was applied.

dopeptidase and trypsin as represented by LE-T-7, LE-T-15, and LE-T-23. All the sequences of the above peptides thus determined were identical to those deduced from the nucleotide sequence of cDNA encoding bcGH (see below); therefore the complete sequence of bcGH was aligned and shown in Fig. 4.

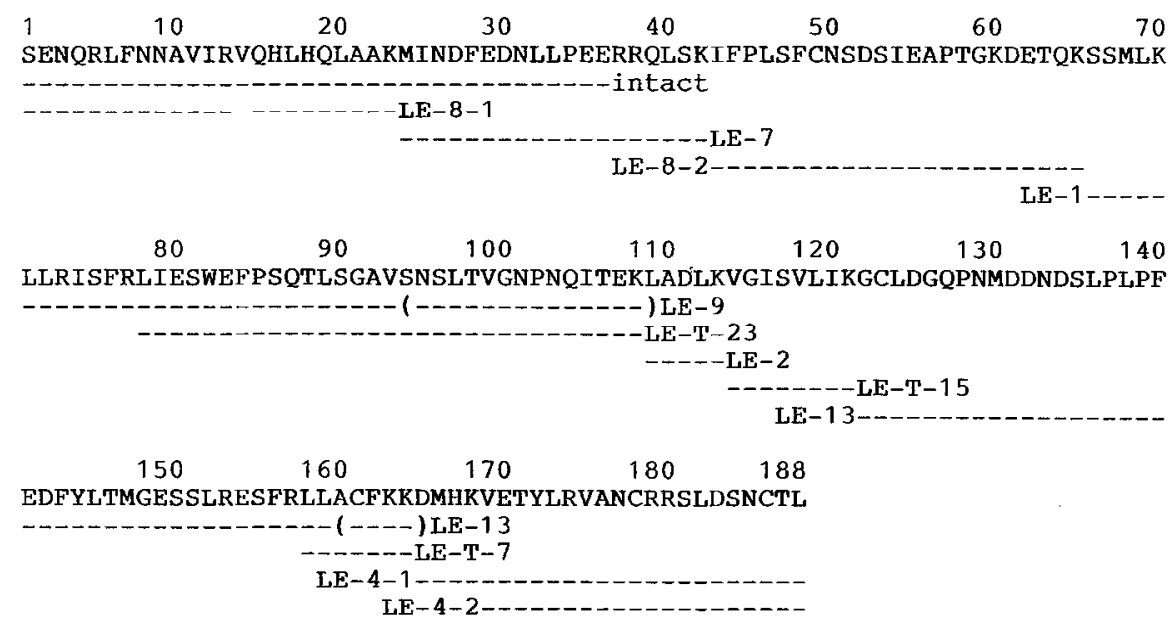

FIG. 4. Primary sequence of bighead carp GH aligned from peptides of lysyl endopeptidase (LE) and lysyl endopeptidase/trypsin (LE-T) digestion. Sequences in parentheses are derived from amino acid composition. 
Isolation and Nucleotide Sequencing of cDNA Encoding bcGH, scGH, and $g c G H$

There were 9,5 , and 13 positive clones obtained from 313,305 , and 295 clones of bighead carp, silver carp, and grass carp pituitary cDNA libraries, respectively. The cDNA of the largest size from each species was subjected to nucleotide sequencing.

The cDNAs encoding bcGH, scGH, and
gcGH were in the range of 1158 to 1171 base pairs (bp) in length. Their nucleotide sequences are almost identical, only differing in a few bases. Consequently, only the sequence of bcGH cDNA was shown (Fig. 5). It contained a 22-bp 5'-noncoding region, a 630-bp open reading frame (ORF), and a 500-bp 3 -untranslated region. The ORF encodes a polypeptide of 210 amino acid residues which includes a leader peptide of 22 residues and a growth hormone of 188

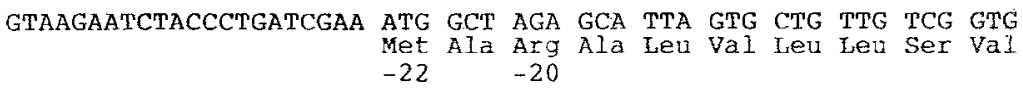

GTG CTG GTT AGT TTG TTG GTG AAC CAG GGG ACG GCC TCA GAG AAC CAG CGG CTC Val Leu Val Ser Leu Leu Val Asn Gln Gly Thr Ala Ser Glu Asn Gln Arg Leu $10 \quad \begin{array}{rr}1 & 1\end{array}$

TTC AAC AAC GCA GTC ATC CGT GTT CAA CAC CTG CAC CAG CTG GCT GCA AAA ATG Phe Asn Asn Ala Val Ile Arg Val Gln His Leu His Gln Leu Ala Ala Lys Met $10 \quad 20$

ATT AAC GAC TTT GAG GAC AAC CTG TTG CCT GAG GAA CGC AGA CAG CTG AGT AAA Ile Asn Asp phe Glu Asp Asn Leu Leu Pro Glu Glu Arg Arg Gln Leu Ser Lys 30

ATC TTT CCT CTG TCT TTC TGC AAC TCT GAC TCC ATT GAG GCG CCC ACT GGA AAA Ile phe pro Leu ser phe Cys Asn ser Asp Ser lle Giu Ala pro rhr Gly Lys $50 \quad 60$ GAT GAA ACG CAG AAG AGC TCT ATG TTG AAG CTC CTT CGC APC PCT TPC CGC CTC Asp Glu Thr Gin Lys Ser Ser Met Leu Lys Leu heu Arg Ile ser phe Arg Led ATT GAG TCC TGG GAG PTC CCC AGC CAG ACC CTG AGC GGA GCC GTC TCA AAC AGC Ile Glu Ser Trp Glu phe Pro ser GIn Thr Leu Ser Gly Ala Val Ser Asn Ser 80

TTG ACC GTC GGT AAC CCC AAC CAG ATC ACT GAG AAG CTG GCC GAC TTG AAA GTG Leu Thr Val Gly Asn pro Asn GIn Ile Thr Glu Lys Leu Ala Asp Leu Lys Val 100 110

GGC ATC AGC GTG CTC ATC AAG GGA TGT CTG GAT GGT CAA CCA AAC ATG GAT GAT Gly Ile Ser Val Leu Ile Lys Gly Cys Leu Asp Gly Gln Pro Asn Met Asp Asp 120 130

AAC GAC TCC CTG CCG CTG CCT TTT GAG GAT TTC TAC TTG ACC ATG GGG GAG AGC Asn Asp Sex Leu pro Leu pro Phe Glu Asp phe Tyr tou Thr Met Gly Glu Ger 140 150 AGC CTC AGA GAG AGC TTT CGT CTT CTG GCT TGC TTC AAG AAG GAC ATG CAC AAG Ser Leu Arg Glu Ser phe Arg Leu Leu Ala Cys phe Lys Lys Asp Met His lys GTG GAA ACT TAC CPA AGG GTT GCA AAT TGC AGG AGA TCC CTG GAT TCA AAC TGC Val Glu Thr Tyr Leu Arg Val Ala Asn Cys Arg Arg Ser Leu Asp Ser Asn Cys 170 180

ACC CTG TAG AGGGCGCCAATGTATTGCTAGCCAAAGCCTGTGACACACTTTGCTGCAAATCTAAAACC

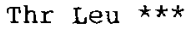
188

AGTTTAAGTCCTCAAAATCTCCTAATATAATTATTATCPGGTTPTATATATGCAGGAAATGTCAACCAGGC ATGGCTAGGTCTGTTCTCTAGCTCCCTCCCATATCTAAACCCTACCTAACACTATTGTATTTATTCTTCTC ATTGGGGAGTGCPCGTAAATTAAAGACATAAGATCTGATTMACATTTCACAGTGGTGCTAAGCAATTTA TGGCGCTATATTTTCAAATGTGCCCAAATCGCTTTGACTCTAGTATTTTATGGCTCCAAAATTGGCTAAAG ATGCCTTTPGTCGAAACTGTCATTPGGATGGATGGGTPCACTCCCAACCAAGTGTATGAATGTAAACATTT GTCTGTCTGATPATGPCCATATTAPTAGCTCATGCTGTTCTCTTGAAGCTGTGTGTCTTTATCCATTAAAG TTCTAAACTGG-POIYA

Fig. 5. Nucleotide sequence and deduced amino acid sequence of cDNA encoding bighead carp GH. 
amino acids. A polyadenylation signal (ATTAAA) is present in the $3^{\prime}$-untranslated region near the polyadenylate tract.

The scGH and gcGH cDNA had the same structure as bcGH cDNA, including a $5^{\prime}$-noncoding region of 28 to $23 \mathrm{bp}$, an ORF of $630 \mathrm{bp}$, and a $3^{\prime}$-untranslated region of 512 to 518 bp. Their ORF also encoded a leader peptide of 22 residues and a $\mathrm{GH}$ of 188 residues. The sequences of scGH and gcGH thus deduced are completely identical to that of bcGH.

\section{DISCUSSION}

In this study, bcGH was monitored in SDS-polyacrylamide gels by assuming that the MW of bcGH is 20,000 . No bioassay was performed. However, there is reason to assume that the fraction thus purified is bcGH because its amino acid sequence is homologous to the known GH sequences of other species (see below). After the complete sequence had been determined, the MW of bcGH was calculated to be 21,101 ,

Bighead carp
Salmon
Tilapia
Tund
Pike eel
Blue shark
Bullfrog
Sea turtle
Chicken
Bovine

Bighead carp Salmon Tilapia Tuna Pike eel Blue shark Bullfrog Sea turtle Chicken Bovine

Bighead carp Salmon Tilapia Tuna Pike eel Blue shark Bullfrog Sea turtle Chicken Bovine

Bighead carp
Salmon
Tilapia
Tuna
Pike eel
Blue shaxk
Bullfrog
Sea turtle
Chicken
Bovine

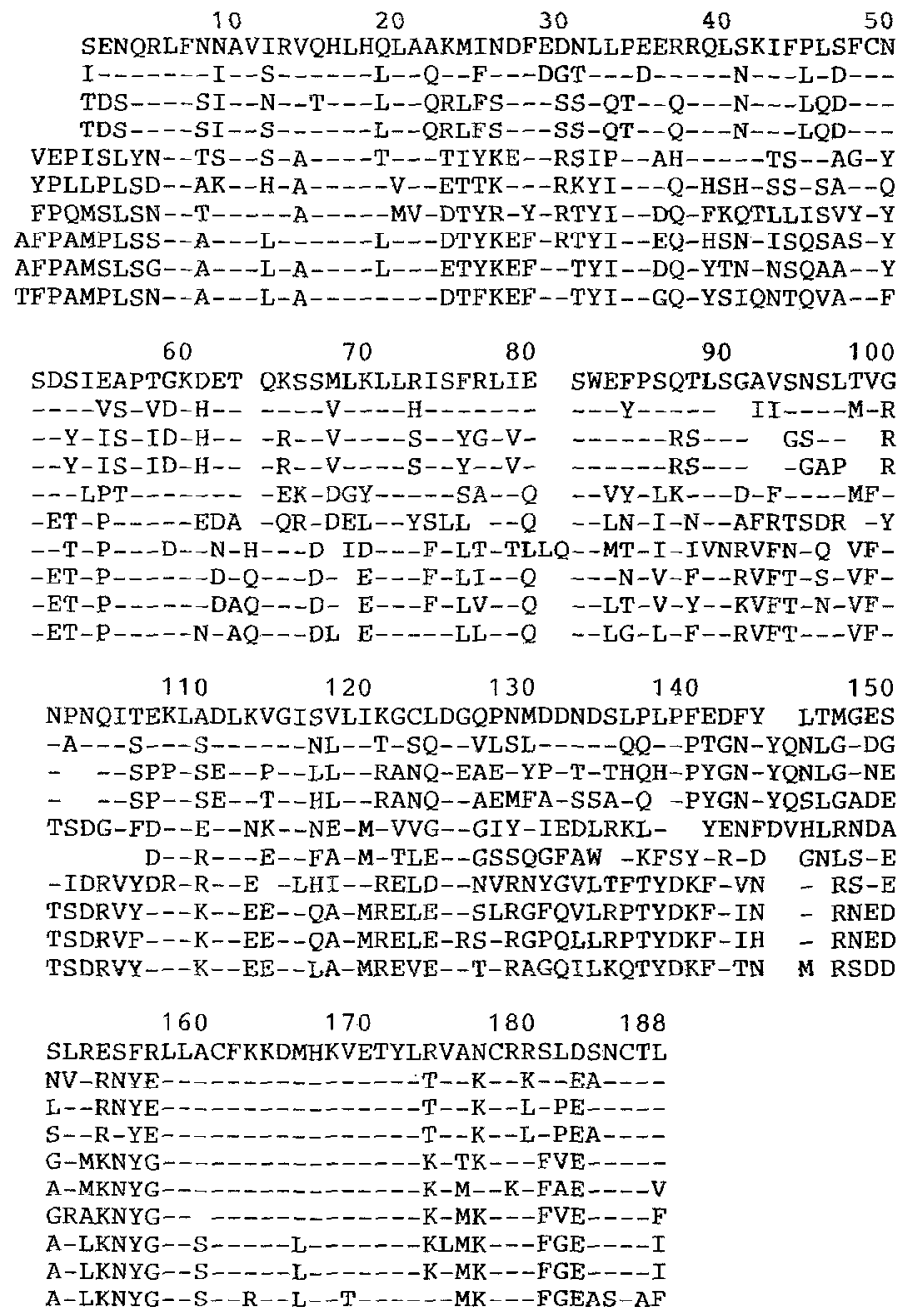

F1G. 6. Primary sequences of $\mathrm{GH}$ of representative species. Dashes indicate residues identical to those of bighead carp GH. References used: salmon, Nicoll et al., 1987; tilapia, Rentier-Delrue et al., 1989; tuna, Sato et al., 1988; pike eel, Liu et al., 1991; blue shark, Yamaguchi et al., 1989; bullfrog, Pan and Chang, 1988; sea turtle, Yasuda et al., 1989; chicken, Souza et al., 1984; bovine, Graf and Li, 1974.

\begin{abstract}
SENQRLFNNAVIRVQHLHQLAAKMINDFEDNLLFEERRQLSKIFPLSFCN

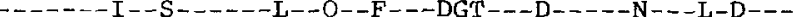
TDS--- SI--N--T---L--QRLFS- -SS-QT--Q--N- - LQD---

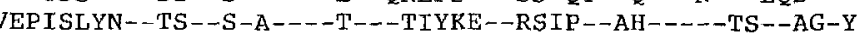
YPLLPLSD- -AK--H-A---- V--ETTK-- RKYI---Q-HSH-SS-SA--Q FPQMSLSN - T-D--A-- - MV-DTYR-Y-RTYI-DQ-FKQTLLISVY - Y DOTL

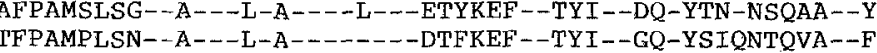

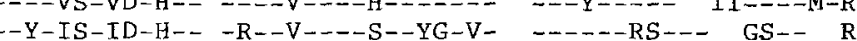
$-\mathrm{Y}-\mathrm{IS}-\mathrm{ID}-\mathrm{H}--\quad-\mathrm{R}--\mathrm{V}----\mathrm{S}--\mathrm{Y}-\sim \mathrm{V}-\quad \sim--\mathrm{RS}---\quad-\mathrm{GAP} \quad \mathrm{R}$

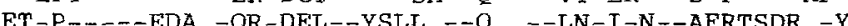

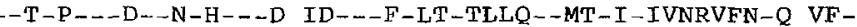
-
ET-P_-_-N-AQ--DD E-----LL--Q - - LG-L-F--RVFT-D-VF-

NPNOITEKLADLKVGISVITKCTLGOPNMDDNDSTPLPFEDF ITMGES A-- S-- S- - - -NL--T-SQ--VLSL-- - -QQD--PTGN-YQNLG-DG - -SPP-SE--P--ILL-RANQ-EAE-YP-T-THQH-PYGN-YQNLG-NE FD--E--NK--NE-M-VVG--GIY-IFDIRKL- YENFDVHLRNDA RS-E RNED RNED SDD

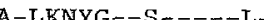
A-LKNYG - S - . - L

A-LKNYG--S - R - L-.T _. - MK - FGEAS AF 
which is very close to the MW of the major band of bcGH determined by SDS-PAGE, and also to those of GHs of other fish species such as salmon (Nicoll et al., 1987) and bonito (Noso et al., 1988). The SDS-PAGE shown in Fig. 2 also revealed that the purified bcGH contained a minor band with MW 40,000. Probably, this is the dimer of bcGH. The dimeric form of human GH has been reported (Lewis et al., 1977).

Protein sequencing by the chemical method requires a large amount of sample and is very time-consuming. We combined the techniques of chemical method and molecular cloning to determine the sequence of bcGH. In the present study, only lysyl endopeptidase and trypsin were used; therefore no overlapping sequences were cotained. The sequencing data from the above peptides were completely fitted with those deduced from bcGH cDNA; therefore these nonoverlapping sequences of bcGH could be aligned. Apparently, the complement of the sequencing data determined by different methods gives a more reliable result.

The primary structures of bcGH, scGH, and gcGH are identical. It is noted that the sequence of gcGH cDNA determined by us was different from that determined by Ho et al. (1989), i.e., 14 nucleotide (nt) substitutions, $1 \mathrm{nt}$ deletion, and $6 \mathrm{nt}$ insertions. The amino acid sequence of gcGH deduced by us had two residues different from those deduced by Ho's group, i.e., $\mathrm{Ser}^{51}$ to $\mathrm{Cys}^{51}$ and $\mathrm{Ala}^{92}$ to $\mathrm{Glu}^{92}$. Whether they are two different forms of gcGH is currently unknown. However, it should be pointed out that serine is the 51st residue of GHs of all species thus far investigated (Fig. 6).

The GHs of four species of Cyprinidae, bighead carp, silver carp, grass carp, and common carp, have five cysteine residues, as opposed to four residues found in other species of fish and tetrapods. Except $\mathrm{Cys}^{123}$, the other four cysteines of cyprinid GHs could be aligned at positions corresponding to those of the GHs of other species. By using these four cysteines as a skeleton and inserting or deleting certain residues, the maximally matched sequences of GHs of various species could be arranged (Fig. 6) and the results of homology analysis are presented in Table 1.

The homology between the GHs of four cyprinid species is very high, up to $94 \%$ (Koren et al., 1989). Such a high degree of GH homology is also observed among various species within the same order of fish, regardless of whether they belong to the same or different families. Examples are $100 \%$ identity between salmon and trout (Salmonidae, Nicoll et al., 1987; Agellon and Chen, 1986) of Salmoniformes, 97\% identity between eel (Anguillidae, Yamaguchi et al., 1987) and pike eel (Muraenesocidae, Liu et al., 1991) of Anguilliformes; and 83 to $91 \%$ identity among tilapia (Ci-

TABLE 1

Homology Analysis of Growth HoRmone

\begin{tabular}{|c|c|c|c|c|c|c|c|c|c|c|}
\hline Species & 1 & 2 & 3 & 4 & 5 & 6 & 7 & 8 & 9 & 10 \\
\hline Bighead carp (1) & 100 & & & & & & & & & \\
\hline Salmon (2) & 68 & 100 & & & & & & & & \\
\hline Tilapia (3) & 56 & 67 & 100 & & & & & & & \\
\hline Tuna (4) & 54 & 66 & 89 & 100 & & & & & & \\
\hline Pike eel (5) & 52 & 48 & 45 & 46 & 100 & & & & & \\
\hline Shark (6) & 49 & 36 & 47 & 42 & 45 & 100 & & & & \\
\hline Frog $(7)$ & 44 & 42 & 43 & 40 & 52 & 53 & 100 & & & \\
\hline Turtle (8) & 45 & 40 & 45 & 40 & 58 & 68 & 64 & 100 & & \\
\hline Chicken (9) & 45 & 40 & 46 & 38 & 57 & 60 & 63 & 89 & 100 & \\
\hline Bovine (10) & 43 & 37 & 38 & 37 & 53 & 61 & 56 & 76 & 78 & 100 \\
\hline
\end{tabular}


chilidae, Rentier-Delrue et al., 1989), tuna (Schombridae, Sato et al., 1988), bonito (Scombridae, Noso et al., 1988), and yellow tail (Carangidae, Watahiki et al., 1988) of Perciformes. On the other hand, the GH homology between the species of different orders is decreased to the range of 48 to $68 \%$ (Table 1). Apparently, the primary structures of fish GHs are relatively conserved within the same order but become diversified between different orders.

The phylogenetic relationship of the primary structures of GHs among vertebrates is presented in Table 1. As expected, GH from one species of fish is more homologous to the GH of other species of fish than it is to the GHs of tetrapods. Although each vertebrate species has its unique $\mathrm{GH}$, all vertebrate GHs share some common features: (1) 4 cysteine residues (except 5 in Cyprinidae) which can form two disulfide bridges; (2) one conserved tryptophan residue at 82 nd position (except 2 residues in blue shark); and (3) four homologous sequences, i.e., residue 6 to 22,60 to 82,110 to 119 and notably 158 to 180 . In addition, a potential glycosylation site (Asn-Cys-Thr) is found in the C-terminal part of GHs of all vertebrates except mammals. Whether the cyprinid GHs are glycosylated as reported in chum salmon (Wagner et al., 1985) is unknown at present.

\section{ACKNOWLEDGMENTS}

The authors thank the National Science Council of the Republic of China for financial assistance. We are grateful for the technical assistance of $\mathrm{Mr}$. W. K. Wong, Mr. C. H. Chang, Mr. S. W. Chen, and Ms. J. M. Chen.

\section{REFERENCES}

Agellon, L. B., and Chen, T. T. (1986). Rainbow trout growth hormone: Molecular cloning of cDNA and expression in Escherichia coli. DNA 5, 463-471.

Barta, A., Richards, R. I., Baxter, J. D., and Shine, J. (1981). Primary structure and evolution of rat growth hormone gene. Proc. Natl. Acad. Sci. U.S.A. 78, 4867-4871.

Chang, C. S., and Liu, C. S. (1988). A picomole-level amino acid analysis by means of gas-phase hydrolysis and DABS-Cl/HPLC method. J. Chinese Biochem. Soc. 17, 12-19.

Chang, Y. S., Huang, C. J., Huang, F. L., Liu, C. S., and Lo, T. B. (1990). Purification, characterization, and molecular cloning of gonadotropin subunits of silver carp (Hypophthalmichtyys molitrix). Gen. Comp. Endocrinol. 78, 23-33.

Chen, H. T., Pan, F. M., and Chang, W. C. (1988). Purification of duck growth hormone and cloning of the complementary DNA. Biochim. Biophys. Acta 949, 247-251.

Graf, L., and Li, C. H. (1974). On the primary structures of pituitary bovine growth hormone. Biochem. Biophys. Res. Commun. 56, 168-176.

Ho, W. K. K., Tsang, W. H., and Dias, N. P. (1989): Cloning of the grass carp growth hormone cDNA. Biochem. Biophys. Res. Commun. 161, 12391243.

Koren, Y., Sarid, S., Ber, R., and Daniel, V. (1989). Carp growth hormone: Molecular cloning and sequencing of cDNA. Gene 77, 309-315.

Lewis, U. J., Peterson, S. H., Bonewald, L. F., Seavey, B. K., and van der Laan, W. P. (1977). An interchain disulfide dimer of human growth hormone. J. Biol. Chem. 252, 3697-3702.

Liu, C. S., Huang, F. L., Chang, Y. S., and Lo, T. B. (1989). Pike eel (Muraenesox cinereus) gonadotropin: Amino acid sequences of both $\alpha$ and $\beta$ subunits. Eur. J. Biochem. 186, 105-114.

Liu, C. S., Wang, Y. C., Chen, J. M., Chang, C. H., Chen, S. W., Huang, F. L., and Lo, T. B. (1991). Primary structure of the pike eel (Muranesox cinereus) growth hormonc. $J$. Chinese Chem. Soc. 38, 97-105.

Martial, J. A., Baxter, J. D., and Goodman, H. M. (1979). Human growth hormone: Complemetary DNA cloning and expression in bacteria. Science 205, 602-607.

Nicoll, C. S., Mayer, G. L., and Russel, S. M. (1986). Structural features of prolactins and growth hormones that can be related to their biological properties. Endocr. Rev. 79, 169-203.

Nicoll, C. S., Steiny, S. S., King, D. S., Nishioka, R. S., Mayer, G. L., Eberhardt, N. L., Baxter, J. D., Yamanaka, M. K., Miller, J. A., Seilhamer, J. J., Schilling, J. W., and Johnson, L. K. (1987). The primary structure of coho salmon growth hormone and its cDNA. Gen. Comp. Endocrinol. 8, 387-399.

Noso, T., Yasuda, A., Kawazoe, I., Takehara, H., Sakai, K., Takahashi, and Kawauchi, H. (1988). Isolation and characterization of growth hormone from an advanced marine fish, Bonito (Katsuwonus pelamis). Int. J. Peptide Protein Res. 32, 579589.

Pan, F. M., and Chang, W. S. (1988). Cloning and se- 
quencing of bullfrog growth hormone complementary DNA. Biochim. Biophys. Acta 950, 238-242.

Rentier-Delrue, F., Swennen, D., Philippart, J. C., L'Hoir, C., Lion, M., Benrubi, O., and Martial, J. A. (1989). Tilapia growth hormone: Molecular cloning of cDNA and expression in Escherichia coli. DNA 8, 271-278.

Sanger, F., Nicklen, S., and Coulson, A. R. (1977). DNA sequencing with chain-terminating inhibitors. Proc. Natl. Acad. Sci. U.S.A. 74, $5463-5467$.

Sato, N., Watanabe, K., Murata, K., Sakaguchi, M., Kariya, Y., Kimura, S., Nonaka, M., and Kimura, A. (1988). Molecular cloning and nucleotide sequence of tuna growth hormone cDNA. Biochim. Biophys. Acta 949, 35-42.

Souza, L. M., Boone, T. C., Murdock, D., Langley, K., Wypych, J., Fènton, D., Johnson, S., Lai, P. H., Evertt, R., Hsu, R. Y., and Bosselman, B. (1984). The application of recombinant DNA techniques to studies on chicken growth hormone. $J$. Exp. Zool. 232, 465-473.

Wagner, G. F., Fargher, R. C., Brown, J. C., and McKeown, B. A. (1985). Further characterization of growth hormone from the chum salmon (Onco- rhynchus keta). Gen. Comp. Endocrinol. 60, 2734.

Watahiki, M., Tanaka, M., Masuda, N., Yamakawa, M., Yoneda, Y., and Nakashima, K. (1988). cDNA cloning and primary structure of yellow tail (Seriola quinqueradiata) pregrowth hormone. Gen. Comp. Endocrinol. 70, 401-406.

Yamaguchi, K., Yasuda, A., Kishida, M., Hirano, T., Sano, H., and Kawauchi, H. (1987). Primary structure of eel (Anguilla japonica) growth hormone. Gen. Comp. Endocrinol. 66, 447-453.

Yamaguchi, K., Yasuda, A., Lewis, U. J., Yokoo, Y., and Kawauchi, H: (1989). The complete amino acid sequence of growth hormone of an Elasmobranch, the blue shark (Prionace glauca). Gen. Comp. Endocrinol. 73, 252-259.

Yamano, Y., Oyabashi, K., Okuno, M. Y., Yato, M., Kioka, N., Manabe, E., Hashi, H., Sakai, H., Komano, T., Utsumi, K., and Iritami, A. (1988). Cloning and sequencing of CDNA that encode goat growth hormone. FEBS Lett. 228, 301-304.

Yasuda, A., Yamaguchi, K., Papkoff, H., Yokon, Y., and Kawauchi, H. (1989). The complete amino acid sequence of growth hormone from the sea turtle (Chelonia mydas). Gen. Comp. Endocrinol. $73,242-251$. 